\title{
Localization of fugitive methane emission from natural gas distribution network of Titas Gas
}

\author{
Pradip C. Mandal ${ }^{* 1,}$, Syed Monjur Morshed ${ }^{2}$ \\ ${ }^{1}$ Universiti Teknologi PETRONAS, Department of Chemical Engineering, 32610 Bandar Seri Iskandar, Perak, Malaysia \\ ${ }^{2}$ Titas Gas Transmission and Distribution Co. Ltd., 105, Kazi Nazrul Islam Avenue, Kawran Bazar, Dhaka-1215, Bangladesh \\ "Corresponding author: e-mail: pradip.mandal@petronas.com.my
}

\begin{abstract}
The aim of this paper is to localize the fugitive leaks from the above ground facilities of the existing system of Titas Gas (TG) after developing mathematical model for fugitive emission. Soap screening techniques and Gasurveyor 500 series instrument were used in this study for detecting potential leaks. Leaked gas was quantified using either Hi-Flow gas sampler or bagging measurements system. The results show that the respective potential gas leaking point of City Gate Station (CGS), commercial Regulating and Metering Station (RMS), industrial RMS, residential RMS and Town Bordering Station (TBS)/ District Regulating Station (DRS) are scrubber dump valve (average leak rate $217.00 \mathrm{~L} / \mathrm{min}$ ), insulating point (average leak rate $4.04 \mathrm{~L} / \mathrm{min}$ ), tube fitting connector (average leak rate $8.00 \mathrm{~L} / \mathrm{min}$ ), connector (average leak rate $1.55 \mathrm{~L} / \mathrm{min}$ ) and pressure relief valve (average leak rate $437.92 \mathrm{~L} / \mathrm{min}$ ). Fugitive methane emission can be reduced by stopping leaks of fittings or components having high $K_{\text {Leak }}$ value.
\end{abstract}

Keywords: fugitive emission, methane release, gas leakage, leak constant, climate mitigation.

\section{INTRODUCTION}

Natural gas is considered one of the cleanest energy sources because the combustion of natural gas results in low $\mathrm{SO}_{2}$ and $\mathrm{NO}_{\mathrm{x}}$ emission and almost no particulate solid or ash content ${ }^{1}$. However, methane (about 19\%), the main constituent of natural gas, is one of the most potent greenhouse gas precursors ${ }^{2}$. It is second only next to carbon dioxide $(64 \%)$ as a contributor to the global warming ${ }^{3}$. Thus, methane emissions from the oil and gas industry have been a major environmental concern for over a long period of time ${ }^{4}$. Natural gas is one of the major energy resources of Bangladesh. Titas Gas (TG) is the premier gas distribution company of Bangladesh which transmits natural gas from gas fields to end users through pipelines. ${ }^{5}$. The gas pipeline has proven to be one of the easiest and safest ways to transport natural gas in Bangladesh. Majority of these pipelines are under ground and passed through crowded cities and remote areas. Only a small part of gas pipelines such as City Gate Station (CGS), Town Bordering Station (TBS), District Regulating Station (DRS), and Regulating and Metering Station (RMS) are above ground. One of the most difficult problems affecting safe and reliable operation of the pipeline system is development of rupture leaks, caused by corrosion and pressure surges ${ }^{6}$. The natural gas will be released through any damage in the pipeline resulting in a hazardous situation developing from possible explosion, fire, injury and damage. Pipeline quality natural gas of TG contains approximately $96.12 \%$ (mol/ mol) methane ${ }^{5}$. Natural gas releases to the atmosphere through fugitive, vented and combusted emissions. Fugitive emissions are unintentional leaks steadily from pipeline and system components, such as flanges, valves, equipment leaks, sampling connections, and open-ended lines ${ }^{7}$ and much later ${ }^{8}$.

A mathematical model of accidental gas release from long transmission pipelines are represented by using of computational fluid mechanics. Literature revealed that the existing hole-model is suitable for predicting gas release through a small punctured hole while the other existing pipe model is suitable to predict the gas release through a complete break in the pipe ${ }^{9,10}$. Yuhu et al. ${ }^{9}$ proposed a new hole-model that lies between the above two situations. Reddy et al. ${ }^{6}$ used a computationally efficient transfer function based state estimation model for dynamic flows in a hypothesis testing framework for developing an approach for leak detection and identification in gas pipeline networks. Moloudi and Esfahani ${ }^{11}$ proposed a unique mass discharge function by surveying dimensionless gas release rate parameters of pipeline rupture. In the same year, Lu et al. ${ }^{12}$ investigated the discharge rate and mass release over time by developing different hole model based on hole diameters. There is no model for representing fugitive emission through above ground facilities of gas transmission and distribution systems in open literature. This paper developed mathematical model to predict fugitive emission from natural gas distribution networks. Zimmerle et al. ${ }^{2}$ discovered that total methane emissions from the transmission and storage of the United States was approximately 1.503 $\mathrm{Gg} / \mathrm{yr}$. Mandal et al..$^{5}$ quantified the leaked methane gas from above ground facilities of the existing system of TG. They discovered that approximately $281.51 \mathrm{MMCM}$ gas is being released on yearly basis whose price was approximately 14.67 M USD. Localization of gas leaks is important to seize these leakages. There are many fittings such as ball valve and piping components such as open ended line are present in the above ground facilities of gas transmission and distribution system. The verbal term 'localize' used in this study is used to identify the piping fittings or components of a specific station where gas leakage are significant.

This work comprises the selected pipe components or fittings where fugitive emission is significant for above ground facilities of natural gas network system. The objective of this paper is to localize the fugitive leaks from the above ground facilities of the existing system of TG by determining the leak constant after developing justified mathematical model. 


\section{MATERIAL AND METHODS}

\section{Fugitive gas released model}

Hole is an opening of pipelines. This anomaly is generated in pipelines due to the rupture of pipelines accidentally or corrosively. The area of a hole is a miserable quantity and gas release from this hole is mathematically expressed by hole model. Moloudi and Esfahani ${ }^{11}$ have expressed gas release model by hole model when the relative diameter (hole size devided by pipe diameter) is less than $15 \%$ and rupture model is used elsewhere. Lu et al. ${ }^{12}$ investigated gas release using the small hole model (hole diameter is less than or equal to $20 \mathrm{~mm}$ ), full bore model (hole diameter is greater than or equal to pipe diameter) and large hole model (hole diameter is greater than $20 \mathrm{~mm}$ but less than pipe diameter). The state of gas in the pipeline is constant and consistent, and flow in the hole is isentropic in the small hole model. In the full bore model, the flow in the pipe is adiabatic, and there is no isentropic expansion from the middle of pipe to the gas releasing point. Large bore model takes into account both the isentropic flow at the hole as the small hole model and the adiabatic flow in the pipe as the full bore model. In 2015, Li et al. ${ }^{13}$ discovered that hole model can predict flow accurately for small leakage holes. Thus these models can predict accidental gas release that is mainly a function of pressure, friction term and hole size. Gas release rate of hole model depends only on relative hole diameter not on pressure and friction term. In the rupture model, gas release rate is a function of friction term and diameter. There is no model for fugitive gas release from pressurized gas pipeline. Small hole model can be used to predict fugitive gas release.

Based on the literature 9 10, 11, 12, 14, the conservation of mass and momentum equations for the steady state subsonic flow of gas through a constant diameter, rigid pipe are:

Equation of state: $\frac{P}{\rho}=\frac{Z R T}{M}$

Continuity equation: $\rho_{1} A_{1} v_{1}=\rho_{2} A_{2} v_{2}$

Poisson equation: $\frac{P_{1}}{\rho_{1}^{\gamma}}=\frac{P_{2}}{\rho_{2}^{\gamma}}$

Energy and momentum balance equation:

$\frac{\gamma+1}{\gamma} \ln \left(\frac{P_{1} T_{2}}{P_{2} T_{1}}\right)+\frac{M}{R G^{2}}\left(\frac{P_{2}^{2}}{T_{2}}-\frac{P_{1}^{2}}{T_{1}}\right)+\frac{4 f L_{e}}{D}=0$

A schematic diagram of gas release through a fugitive point is shown in Figure 1. Several assumptions are made: the gas flows adiabatically in the pipeline and isentropically as a one-dimension model at the release point, pressure inside the pipeline will not be affected by gas release. Therefore, the gas release rate is constant and equal to the initial maximum release rate. The expression of gas release rate can be obtained by substituting Eq. (1), Eq. (2) and Eq. (3) into Eq. (4).

$Q=C_{d} A_{d} P_{2} \sqrt{\frac{2 \mathrm{M}}{Z R T_{2}} \frac{\gamma}{\gamma-1}\left[\left(\frac{P_{a}}{P_{2}}\right)^{\frac{2}{\gamma}}-\left(\frac{P_{a}}{P_{2}}\right)^{\frac{\gamma+1}{\gamma}}\right]}$

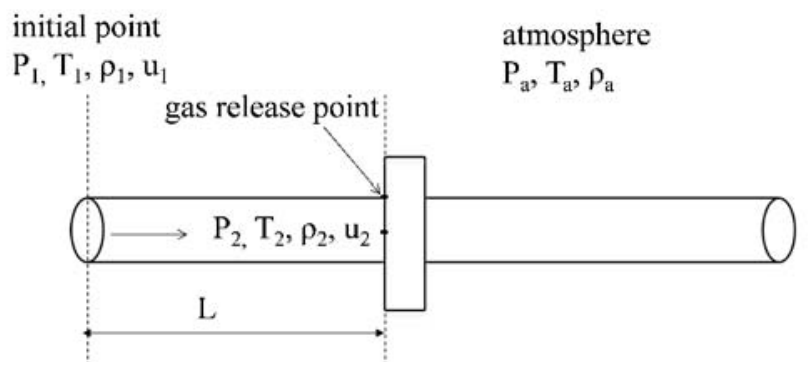

Figure 1. Schematic diagram of gas release

This equation demonstrates hole model. The empirical discharge coefficient, $C_{d}$, have a fixed value either 0.61 (for subsonic of Reynolds number greater than 30,000) or 1 (for other situations). The gas leaking area, $A_{d}$, is very small and not a measurable quantity. Thus, the product of $C_{d}$ and $A_{d}$ can be considered as a constant value for a particular fugitive gas release and express as . Inserting in Eq. (5), the expression of gas release rate can be written as

Or, $Q=K_{\text {Leak }} P_{2} \sqrt{\frac{2 M}{Z R T_{2}} \frac{\gamma}{\gamma-1}\left[\left(\frac{P_{a}}{P_{2}}\right)^{\frac{2}{\gamma}}-\left(\frac{P_{a}}{P_{2}}\right)^{\frac{\gamma+1}{\gamma}}\right]}$

The value of release rate at the leaking point depends on whether gas flow is sonic or subsonic. This is decided by the critical pressure ratio (CPR):

$C P R=\frac{P_{a}}{P_{2 c r}}=\left(\frac{2}{\gamma+1}\right)^{\frac{\gamma}{\gamma-1}}$

When $P_{2}>P_{2 c r}$, the gas release will be considered as the sonic flow at the gas leaking point and the expression of gas release rate is obtained by substituting Eq. (7) into Eq. (6).

$Q=K_{\text {Leak }} P_{2} \sqrt{\frac{M}{Z R T_{2}} \gamma\left(\frac{2}{\gamma+1}\right)^{\frac{\gamma+1}{\gamma-1}}}$

This mathematical model can predict fugitive natural gas emission. But this model can also be utilized to predict emissions of any gasses or vapour from pressurized equipment due to leaks and other unintended or irregular release of gasses, mostly for industrial activities.

\section{Field data collection and released gas quantification}

TG serves 1.535.592 customers (domestic: 1.519.124, commercial: 10.530, industrial including power and fertilizer: 5.938) through $12.152 .53 \mathrm{~km}$ (diameter: 19.05 $\mathrm{mm}-609.6 \mathrm{~mm}$ ) constructed pipelines and 129 stations (CGS/TBS/DRS/RMS/M\&R). All constructed pipelines are below ground and only 129 stations and 1.535 .592 customers RMS are above ground. Data were collected from the above ground facilities of TG. Figure 2 depicts the gas distribution network of TG and work boundary of the work. The data were collected based on field survey. The numbers of stations to be surveyed are determined using simple random sampling techniques considering $99 \%$ of the stations have a leak for CGS, $60 \%$ of the stations have a leak for TBS/DRS and $40 \%$ of the stations have a leak for customers' RMS. The Simple Random Sampling formulas are given below: 


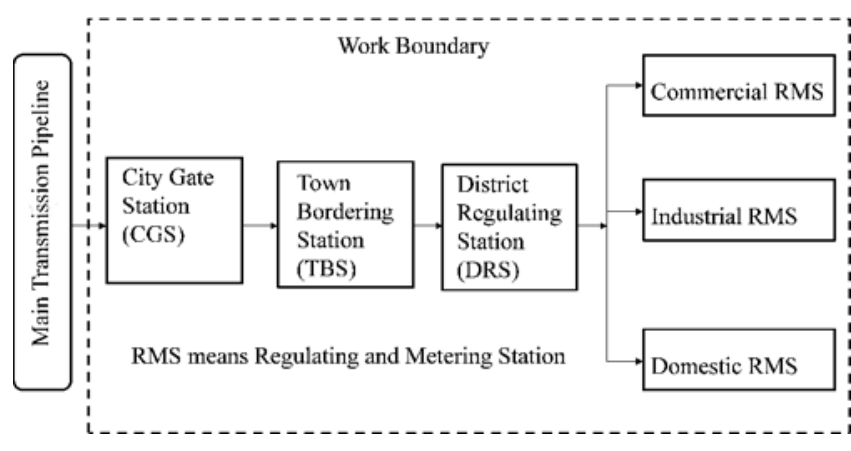

Figure 2. Titas gas distribution network and work boundary

$n=\frac{1.96^{2} N V}{(N-1) \times 0.1^{2}+1.96^{2} V}$

where, $V=\frac{p(1-p)}{p^{2}}$

Based on calculation, approximately 2 CGSs out of 4, $6 \mathrm{TBSs} / \mathrm{DRSs}$ out of 125, 58 Industrial RMSs out of 5.938, 115 Commercial RMSs out of 10,530 and $403 \mathrm{Re}-$ sidential RMSs out of 1.519.124 are surveyed discretely and gas leakage rate for all possible gas leaking points such as ball valve, insulating joint (IJ), pressure relief valve (PRV), scrubber dump valve (SDV), tube fitting connector (TFC), valve packing (VP) are recorded for analysis. The average gas leakage rate data of all potential gas leaking points were used in this study.

Leak identification, released gas quantification and $K_{\text {Leak }}$ determination were the key processes of this work (Fig. 3). Gas leakages were detected using soap screening techniques and catalytic oxidation/ thermal conductivity detectors device, Gasurveyor 500 series instrument which is a most flexible range of gas detectors developed by Gas Measurement Instruments Ltd. (GMIL). Two wellknown leak measurement technologies, Hi-Flow gas sampler, a portable device developed by Gas Research Institute (GRI), and bagging measurements technology were used in this study. These leak detection and quantification techniques are recommended by the United States Environmental Protection Agency (USEPA) and the United Nations Framework Convention on Climate Change (UNFCCC) ${ }^{\mathbf{1 5}, \mathbf{1 6}}$. Hi-Flow samplers' measure leak rates up to 0.30 cubic meters per minute, with the accuracy of calculated leak rate of $\pm 5 \%{ }^{17}$. Bagging measurements technology is the appropriate choice for measuring high leaking rate (greater than 0.30 cubic meters per minute). The leaking area was confined using polyethylene plastic to quantify the releasing gas as shown in Fig. 4. For methane $(\gamma=1.3)$ the CPR $\left(P_{a} / P_{2 c r}\right)$ is $0.55^{18}$. If the value of $P_{2}$ is greater than $P_{2 c r}$, the gas release is known as sonic release where the

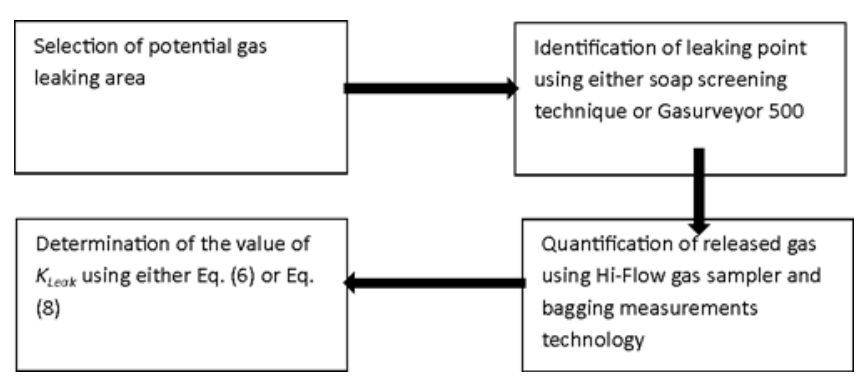

Figure 3. Leak identification, released gas quantification and KLeak determination process

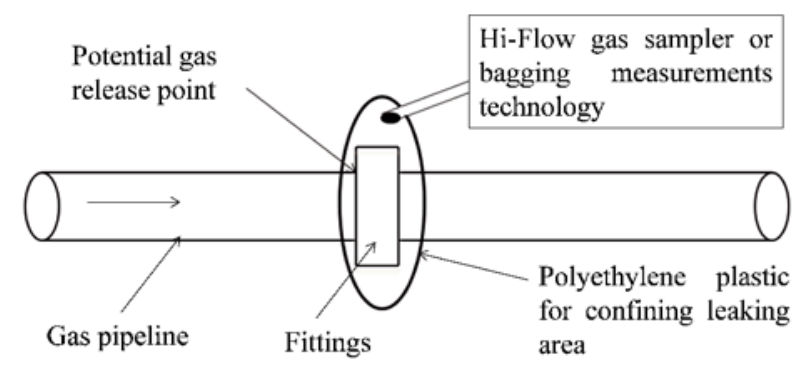

Figure 4. Quantification of released gas

Mach number $(M a=v / c)$ at the gas exit point is unity. The values of $K_{\text {Leak }}$ were determined using Eq. (6) for sub-sonic flow and Eq. (8) for sonic flow.

\section{RESULTS AND DISCUSSION}

Literature revealed that fugitive methane emissions from the Canadian conventional oil and gas sector account for about $50 \%$ of the greenhouse gas emissions ${ }^{3}$. Zimmerle et al. ${ }^{2}$ disclosed that transmission fugitive emission of United States were $64 \%$ of total emission. Total estimated fugitive emission from above ground facilities of TG was approximately $4.214 \mathrm{MMTCO}_{2} \mathrm{e} / \mathrm{y}$ which was $4.09 \%$ of the total methane emission from human activities in Bangladesh (Mandal et al. ${ }^{\mathbf{5}}$ 2015). Currently, TG has no advanced leak detection and repair (LDAR) program for detecting, measuring and repairing potential leaks to boost methane emission from gas distribution networks ${ }^{5}$. Localization of gas releasing points for each potential gas distribution sectors of $\mathrm{TG}$ according to their intensity is vital to seize gas release to the atmosphere on priority basis. To meet the objective of this paper, gas leak constant $\left(K_{\text {Leak }}\right)$ was determined followed by evaluating gas leak rate from individual equipment or gas leaking points.

For evaluating gas leak constant, gas leak rate at different fittings of the above ground facilities of TG distribution system are practically collected and the data are tabulated in Table 1 . The results show that the respective potential gas leaking point of CGS, commercial RMS, industrial RMS, residential RMS and TBS/DRS are SDV (average leak rate $217.00 \mathrm{~L} / \mathrm{min}$ ), IJ (average leak rate $4.04 \mathrm{~L} / \mathrm{min}$ ), TFC (average leak rate $8.00 \mathrm{~L} /$ $\mathrm{min}$ ), connector (average leak rate $1.55 \mathrm{~L} / \mathrm{min}$ ) and PRV (average leak rate $437.92 \mathrm{~L} / \mathrm{min}$ ). The main function of CGS, TBS and DRS is to regulate pressure according to the distribution line specifications and customers' requirements. These stations contain similar types of fittings. PRVs are the major leaking point of TBS/DRS due to high line pressure, fault of pressure setting and mechanically disorder of the equipment. SDV is the second leaking point of TBS/DRS and main leaking point of CGS due to the loose connections. Valves presented in CGS, TBS/DRS are not leaking prone area. Most of the IJs of CGS, TBS/DRS are installed under the ground and underground parts of distribution networks were not included under this work. Comparing to the CGS (average leaking rate $25.35 \mathrm{~L} / \mathrm{min}$ ) and TBS/DRS, TBS/ DRS (average leaking rate $66.68 \mathrm{~L} / \mathrm{min}$ ) is the leaking prone stations of TG. The commercial RMS, industrial RMS and residential RMS were basically installed to deliver gas to the respective commercial, industrial and 
Table 1. Gas leak rate at individual equipment or points

\begin{tabular}{|c|c|c|c|c|c|c|c|c|c|c|}
\hline \multirow{2}{*}{$\begin{array}{l}\text { Source of } \\
\text { Leak }\end{array}$} & \multicolumn{2}{|c|}{$\mathrm{CGS}^{\dagger}$} & \multicolumn{2}{|c|}{$\mathrm{TBS}^{\dagger} / \mathrm{DRS}^{\dagger}$} & \multicolumn{2}{|c|}{ Industrial $\mathrm{RMS}^{\dagger}$} & \multicolumn{2}{|c|}{ Commercial RMS $^{\dagger}$} & \multicolumn{2}{|c|}{ Residential RMS } \\
\hline & $\begin{array}{l}\mathrm{AP}^{\ddagger} \\
{[\mathrm{kPa}]}\end{array}$ & $\begin{array}{l}\mathrm{ALR}^{\ddagger} \\
{[\mathrm{L} / \mathrm{min}]}\end{array}$ & $\begin{array}{l}\mathrm{AP}^{\ddagger} \\
{[\mathrm{kPa}]}\end{array}$ & $\begin{array}{l}\mathrm{ALR}^{\ddagger} \\
{[\mathrm{L} / \mathrm{min}]}\end{array}$ & $\begin{array}{l}\mathrm{AP}^{\ddagger} \\
{[\mathrm{kPa}]}\end{array}$ & $\begin{array}{l}\mathrm{ALR}^{\ddagger} \\
{[\mathrm{L} / \mathrm{min}]}\end{array}$ & $\begin{array}{l}\mathrm{AP}^{\ddagger} \\
{[\mathrm{kPa}]}\end{array}$ & $\begin{array}{l}\mathrm{ALR}^{\ddagger} \\
{[\mathrm{L} / \mathrm{min}]}\end{array}$ & $\begin{array}{l}\mathrm{AP}^{\ddagger} \\
{[\mathrm{kPa}]}\end{array}$ & $\begin{array}{l}\mathrm{ALR}^{\ddagger} \\
{[\mathrm{L} / \mathrm{min}]}\end{array}$ \\
\hline Ball valve & & 0 & & 0 & & 0.50 & & 0 & & 0 \\
\hline Connector & 1034.21 & 0.92 & 379.21 & 5.07 & 137.90 & 2.13 & 137.90 & 2.53 & 124.11 & 1.55 \\
\hline Flange & & 1.70 & & 0.90 & & 1.20 & & 0 & & 0 \\
\hline $\mathrm{IJ}^{*}$ & & 0 & & 0 & & 0 & & 4.04 & & 1.22 \\
\hline $\mathrm{PRV}^{*}$ & & 0.80 & & 437.92 & & 4.63 & & 0 & & 0 \\
\hline Regulator & & 0 & & 16.78 & & 0 & & 0.20 & & 0 \\
\hline $\mathrm{SDV}^{*}$ & & 217.00 & & 116.79 & & 0 & & 0 & & 0 \\
\hline TFC* & & 0 & & 19.00 & & 8.00 & & 0.70 & & 0 \\
\hline $\mathrm{VP}^{*}$ & & 7.73 & & 3.66 & & 0.62 & & 0.45 & & 0.65 \\
\hline
\end{tabular}

† CGS means City Gate Station; RMS means Regulating and Metering Station; TBS means Town Bordering Station; DRS means District Regulating Station.

${ }^{\ddagger}$ AP means Average Pressure; ALR means Average Leak Rate.

*IJ means Insulating Joint; PRV means Pressure Relief Valve; SDV means Scrubber Dump Valve; TFC means Tube Fitting Connector; VP means Valve Packing.

residential types of customers. The average leak rate of residential customers $(0.38 \mathrm{~L} / \mathrm{min})$ is the least amongst all types of customers due to the highest density of customers $(98.93 \%)$. But total gas emission to the atmosphere from residential sector is the highest amongst all types of customer as approximately 1.519 .124 customers of total 1.535.592 customers fall under this category. Therefore, residential sector is the vital gas emission sector of all types of customers. Connectors and insulating joints are two vital leaking areas for residential and commercial RMS due to the loose connection and fault of the fittings or materials.

Considering the leak rate tabulated in Table 1, the leak constant $\left(K_{\text {Leak }}\right)$ is calculated using Eq. (6) and Eq. (8). The calculated values of $K_{\text {Leak }}$ at different fittings and piping components of the above ground facilities of TG distribution system are displayed in Table 2 . The values of $K_{\text {Leak }}()$ are the indication of fugitive emission areas. The higher the $K_{\text {Leak }}$ value, the higher the gas releasing area. According to the $K_{\text {Leak }}$ values the potential gas leaking fittings or piping components are pointed out as follows:

CGS: SDV $>$ VP $>$ Flange $>$ Connector $>$ PRV

TBS/DRS: PRV $>$ SDV $>$ Regulator $>$ TFC $>$ Connector $>$ VP Industrial RMS: TFC $>$ PRV $>$ Connector $>$ Flange $>$ VP $>$ Ball Valve

Commercial RMS: IJ $>$ Connector $>$ TFC $>$ VP $>$ Regulator

Residential RMS: Connector $>$ IJ $>$ VP.

Therefore, PRV, connector and VP are the common gas leaking points for each station. IJs of commercial and residential RMS are potential gas leaking points.
In residential and commercial RMS, insulated union, a serviceable connection, is used as an insulating joint. All distribution pipelines of TG are cathodically protected for corrosion. Insulating joints act as an interruption point in the metallic or conductive path between a pipeline and its associated fittings or equipment. This insulated union is easily broken down due to vibration and force imbalance. Connectors are required to connect pipes with fittings and equipment such as regulator. Gas can leak from connectors due to loose fittings. It is vital for TG to seize these leakages for reducing environmental burden. TG can replace the insulated union on regular basis or use high quality insulated union, faulty equipment, fittings or piping components and refit the loose connection to seize leakages adopting LDAR program.

\section{CONCLUSIONS}

This study demonstrated that SDV and VP of CGS; PRV, SDV, TFC and regulator of TBS/DRS; flange and connector of commercial RMS; TFC and PRV of industrial RMS and connector and IJ of residential RMS are major gas releasing fittings or components of the gas distribution system of TG. The values of $K_{\text {Leak }}$ are the indication of fugitive emission areas and the higher the $K_{\text {Leak }}$ value, the higher the gas releasing area. Fugitive natural gas emission can be reduced by seizing leaks of fittings or components those have high $K_{\text {Leak }}$ value. Leaks from IJs of commercial and residential RMS; and common leaks from PRV, connector and VP of other stations are needed to stop on priority basis. TG can

Table 2. The values of $K_{\text {Leak }}$ at individual equipment or points

\begin{tabular}{|c|c|c|c|c|c|c|c|c|c|c|}
\hline \multirow{2}{*}{$\begin{array}{l}\text { Source of } \\
\text { Leak }\end{array}$} & \multicolumn{2}{|c|}{$\mathrm{CGS}^{\dagger}$} & \multicolumn{2}{|c|}{ TBS $^{t} / \mathrm{DRS}^{\dagger}$} & \multicolumn{2}{|c|}{ Industrial RMS ${ }^{\dagger}$} & \multicolumn{2}{|c|}{ Commercial RMS ${ }^{\dagger}$} & \multicolumn{2}{|c|}{ Residential RMS $^{\dagger}$} \\
\hline & $P_{a} / P_{2}$ & $\begin{array}{c}K_{\text {Leak }} \\
\times 10^{-10} \\
{\left[\mathrm{~m}^{2}\right]} \\
\end{array}$ & $P_{a} / P_{2}$ & $\begin{array}{c}K_{\text {Leak }} \\
\times 10^{-10} \\
{\left[\mathrm{~m}^{2}\right]}\end{array}$ & $P_{a} / P_{2}$ & $\begin{array}{c}K_{\text {Leak }} \\
\times 10^{-10} \\
{\left[\mathrm{~m}^{2}\right]}\end{array}$ & $P_{a} / P_{2}$ & $\begin{array}{c}K_{\text {Leak }} \\
\times 10^{-10} \\
{\left[\mathrm{~m}^{2}\right]}\end{array}$ & $P_{a} / P_{2}$ & $\begin{array}{c}K_{\text {Leak }} \\
\times 10^{-10} \\
{\left[\mathrm{~m}^{2}\right]} \\
\end{array}$ \\
\hline Ball valve & & 0 & & 0 & & 3.04 & & 0 & & 0 \\
\hline Connector & 0.1788 & 1.77 & 0.4225 & 16.00 & 0.8483 & 12.97 & 0.8483 & 15.40 & 0.9001 & 10.01 \\
\hline Flange & & 3.28 & & 2.84 & & 7.30 & & 0 & & 0 \\
\hline $\mid \mathrm{JJ}^{*}$ & & 0 & & 0 & & 0 & & 24.59 & & 7.88 \\
\hline $\mathrm{PRV}^{*}$ & & 1.54 & & 1381.94 & & 28.18 & & 0 & & 0 \\
\hline Regulator* & & 0 & & 52.95 & & 0 & & 1.22 & & 0 \\
\hline SDV $^{*}$ & & 418.60 & & 368.55 & & 0 & & 0 & & 0 \\
\hline TFC $^{*}$ & & 0 & & 59.96 & & 48.70 & & 4.26 & & 0 \\
\hline$V P^{*}$ & & 14.91 & & 11.55 & & 3.77 & & 2.74 & & 4.20 \\
\hline
\end{tabular}

+ CGS means City Gate Station; RMS means Regulating and Metering Station; TBS means Town Bordering Station; DRS means District Regulating Station.

*IJ means Insulating Joint; PRV means Pressure Relief Valve; SDV means Scrubber Dump Valve; TFC means Tube Fitting Connector; VP means Valve Packing. 
reduce gas leak to the atmosphere by replacing faulty equipment, fittings or piping components and refitting loose connections by enforcing LDAR program. By reducing methane release to the atmosphere, TG can increase their revenues parallel to uphold their image to the international bodies.

\section{ACKNOWLEDGEMENT}

This work was supported by the Titas Gas Transmission and Distribution Company Limited for the project of Certified Emission Reductions (CERs) under Clean Development Mechanism (CDM). This work was also supported by the Universiti Teknologi PETRONAS.

\section{NOMENCLATURE}

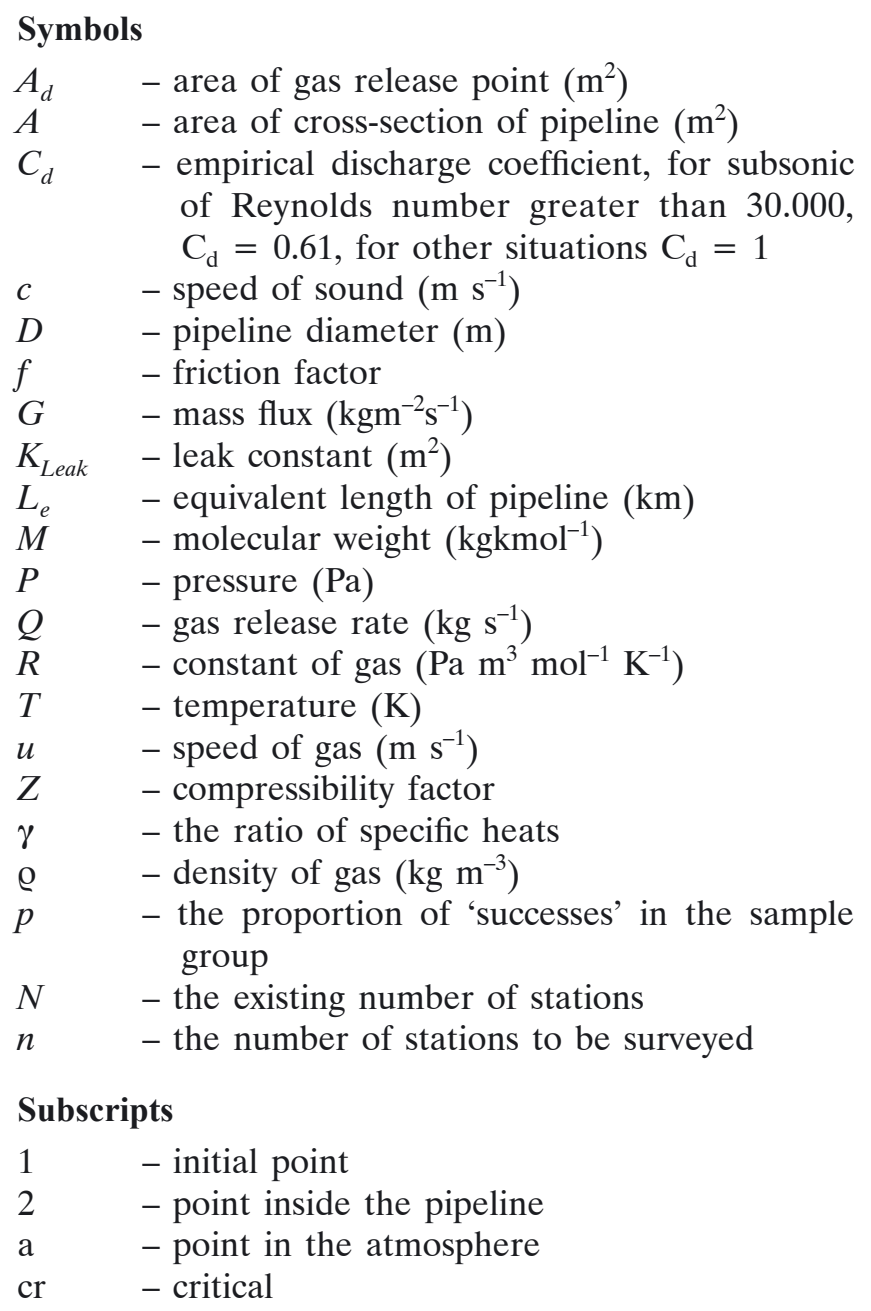

\section{REFERENCES}

1. Safitri, A., Gao, X. \& Mannan, M.S. (2011). Dispersion Modeling Approach for Quantification of Methane Emission Rates from Natural Gas Fugitive Leaks Detected by Infrared Imaging Technique. J. Loss. Prevent. Proc. 24, 138-145. DOI: 10.1016/J.JLP.2010.11.007.

2. Zimmerle, D.J., Williams, L.L., Vaughn, T.L., Quinn, C., Subramanian, R., Duggan, G.P., Willson, B., Opsomer, J.D., Marchese, A.J., Martinez, D.M. \& Robinson, A.L. (2015). Methane emissions from the natural gas transmission and storage system in the United States. Environ. Sci. Technol. 49, 9374-9383. DOI: 10.1021/acs.est.5b01669.

3. Litto, R., Hayes, R.E. \& Liu, B. (2007). Capturing Fugitive Methane Emissions from Natural Gas Compressor
Buildings. J. Environ. Manage. 84(3), 347-361. DOI: 10.1016/J. JENVMAN.2006.06.007.

4. Agarwal, A. (2011). Evaluation of Fugitive Methane Emission Factor for Oil and Gas in India. SPE International, SPE 144628, 1-12. DOI: http://dx.doi.org/10.2118/144628-MS.

5. Mandal, P.C., Chowdhury, S. \& Morshed S. (2015). Fugitive Methane Emission from Natural Gas Distribution Network of Titas Gas and Environmental Risk. Energy and Sustainability V: Special Contributions, WIT Press, 137-148.

6. Reddy, H.P., Narasimhan, S., Bhallamudi, S.M. \& Bairagi, S. (2011). Leak Detection in Gas Pipeline Networks Using an Efficient State Estimator. Part-I: Theory and simulations. Comput. Chem. Eng. 35, 651-661. DOI: 10.1016/J.COMPCHEMENG.2010.10.006.

7. Jelinek, K.A., Rooney T.C. \& Webb M.G. (1993). Fugitive Emissions from an Offshore Oil and Gas Production Platform. SPE International, SPE 25943, 119-124. DOI: http://dx.doi. org/10.2118/25943-MS.

8. Nwaoha, C. (2010). Controlling Fugitive Emissions in Nigeria's Oil and Gas Industry: Proper Sealing Device Selection a Panacea. SPE International, SPE 140675, 1-9. DOI: 10.2118/140675-MS.

9. Yuhua, D., Huilin, G., Jing'en, Z. \& Yaorong, F. (2002). Evaluation of gas release rate through holes in pipelines. J. Loss. Prevent. Proc. 15(6), 423-428. DOI: 10.1016/S09504230(02)00041-4.

10. Yuhu, D., Huilin, G., Jing'en, Z. \& Yaorong, F. (2003). Mathematical Modeling of Gas Release through Holes in Pipelines. Chem. Eng. J. 92, 237-241. DOI: 10.1016/S13858947(02)00259-0.

11. Moloudi, R. \& Esfahani, J.A. (2014). Modeling of gas release following pipeline rupture: Proposing non-dimensional correlation. J. Loss. Prevent. Proc. 32, 207-217. DOI: 10.1016/J. JLP.2014.09.003.

12. Lu, L., Zhang, X., Yan, Y., Li, J.M. \& Zhao, X. (2014). Theoretical Analysis of Natural-Gas Leakage in Urban Mediumpressure Pipelines. J. Environ. Hum. 1(2), 71-86. Retrieved on March 10, 2016, from http://www.scipublish.com/journals/ $\mathrm{EH} /$ papers/520.

13. Li, K., Zhou, X., Tu, R., Yi, J. \& Jiang, X. (2015). Experimental investigation of $\mathrm{CO}_{2}$ accidental release from a pressurised pipeline. Energ. Proced. 75, 2221-2226. DOI: 10.1016/J.EGYPRO.2015.07.388.

14. Ivings, M.J., Clarke, S., Gant, S.E., Fletcher, B., Heather, A., Pocock, D.J., Pritchard, D.K., Santon, R. \& Saunders, C.J. (2008). Area Classification for Secondary Releases from Low Pressure Natural Gas Systems, In site: Modelling Gas Leaks. Health and Safety Laboratory, Health and Safety Executive, RR630 Research Report, Crown copyright 2008, UK, 14-18. Retrieved on March 10, 2016, from http://www.hse.gov.uk/ research/rrpdf/rr630.pdf.

15. OAQPS (2014). Oil and Natural Gas Sector Leaks Report for Oil and Natural Gas Sector Leaks. U.S. EPA Office of Air Quality Planning and Standards (OAQPS), 1-63. Retrieved on March 10, 2016, from https://www3.epa.gov/airquality/oilandgas/2014papers/20140415leaks.pdf.

16. UNFCCC (2012). Reducing gas leakages within the Moldovagaz distribution network. Republic of Moldova, United Nations Framework Convention on Climate Change (UNFCCC), Project 6194. Retrieved on March 10, 2016, from https://cdm. unfccc.int/Projects/DB/TUEV-RHEIN1336622539.87/view.

17. Mandal, P.C. (2014). Gas Leak Detection in Pipelines \& Repairing System of Titas Gas. J. Appl. Eng. 2(2), 23-34. Retrieved on March 10, 2016, from http://joae.org/index.php/ joae/article/view/7/6.

18. Citizendium (2016). Specific heat ratio. The Citizens' Compendium. Retrieved on September 3, 2016, from http:// en.citizendium.org/wiki/Special:BookSources/0070697167. 